\title{
The impact of care for grandchildren on the supports for elderly parents of first-generation only-child parents in urban China
}

\author{
Haixia Wu ${ }^{1}$ \\ Received: 20 November 2018 / Accepted: 15 February 2019 / Published online: 4 March 2019 \\ (c) China Population and Development Research 2019
}

\begin{abstract}
The support elderly parents receive from their grown-up children and the care they provide for grandchildren reflect the intergenerational relationships in Chinese families. Using data on only-child families in urban China from a 2015 survey conducted by the Institute of Population and Labor Economics, Chinese Academy of Social Sciences, this paper studies the status of care provided for grandchildren by parents of first-generation only-child in urban China and considers the effects this support has on the elderly. The data shows that over $80 \%$ of only-children parents have cared for their grandchildren. Most only-children also provide support for their elderly parents. Care for grandchildren provided by grandparents increases the economic and housekeeping support for the elderly provided by only-children. Only-children are the main beneficiaries of the intergenerational support that comes from the care for grandchildren provided by elderly parents. If the elderly parents have adequate retirement income and have little or no need for financial support, such intergenerational support resembles "altruism". However, if the elderly parents do not have adequate retirement income, the satisfaction of their needs depends on resources like time and money available to their only-children.
\end{abstract}

Keywords The first-generation only-children · Family supports for the elderly $\cdot$ Care for grandchild · Urban China

\section{Introduction}

Beginning in 1970, the Chinese government began promoting a family planning policy that called for late marriage, 4-year birth spacing and only two children per family nationwide. In 1980, this policy became the One-Child Policy. As a result

Haixia Wu

wuhx@cass.org.cn

1 Institute of Population and Labor Economics, Chinese Academy of Social Sciences, Beijing, China 
of these policies, since the 1970s China has undergone a rapid demographic transition, changing from a country with "high birth rate, low mortality rate, and high population growth rate" to a country with a population growth model featuring "low birth rate, low mortality rate, and low population growth rate." Family planning policies have not only changed the basic structure and overall development trends of the Chinese population, they have also changed the structure of Chinese families. Due to strict implementation of the One-Child Policy, a huge group of only-children emerged. It is estimated that China has 80-120 million only-children (Yang and Guo 2000; Song 2005; Feng 2006; Wang 2009), and that most of these only-children were born in cities. Today, the first-generation of only-children have grown up, married and have children of their own, and their parents have gradually entered old age. Historically, the family has always been the major source of support for the elderly in both urban and rural China. That many elderly parents only have one child to support them in their old age has become an issue of concern to the entire society.

Family support reflects the intergenerational relationship. In China, intergenerational family relationships include obligations, responsibilities, power and exchange relationships, and shared kinship among intergenerational family members (Wang 2008). In practical terms, the care for grandchildren by grandparents is a concrete manifestation of the intergenerational family relationship, and supports the existence of beneficial emotional relationships between the elderly parents and their grownup children (Giarrusso et al. 2000; Triadó et al. 2014). It has also been determined that caring for grandchildren, as an intergenerational exchange between parents and grown-up children, can improve the support provided by adult-children for their older parents in rural China (Song and Li 2010). In addition, most first-generation only-children in urban China are in the formative stages of their careers; they need to balance work and family life, especially the care for babies and young children. Undoubtedly, having grandparents care for grandchildren is a great help to the grown-up children. Currently, how many elderly parents of only-children care for their grandchildren? Does care for grandchildren by grandparents have an impact on the supports for elderly parents provided by only-children? The data from the survey of only-children families in urban China helps to provide answers to these questions.

This paper uses data from the survey on the status of only-child families in urban China to examine the effects of care for grandchildren by grandparents on supports for elderly parents provided by only-children in urban China. The results also help to illuminate the characteristics of intergenerational relationships in only-child families in urban China. Here care for grandchildren by grandparents may take place before the time of the survey or at the time of the survey.

\section{Literature review}

Care for grandchildren is a kind of intergenerational support that elderly parents give their married children. Grandparents may be occasional babysitters or full-time caregivers for their grandchildren; customs and practices differ significantly from place to place. In the US, $40 \%$ of grandparents help to care for the grandchildren of their working adult offspring for at least $50 \mathrm{~h}$ each year (Hughes et al. 2007). In Europe, 
40-60\% of grandparents occasionally care for grandchildren (Attias-Donfut et al. 2005), and in Korea, about $6 \%$ of grandparents do so (Ko and Hank 2014). Unlike current practices in many Western families, acting as care providers for grandchildren is a family role taken on by the elderly in China. Data from the China Health and Retirement Longitudinal Study (CHARLS) in 2008 showed that approximately $58 \%$ of grandparents cared for their grandchildren (Ko and Hank 2014).

As a kind of intergenerational support between parents and married child, caring for grandchildren represents a transfer of time, money and other resources from elderly parents to their grown-up children. This kind of parent-child intergenerational support takes different forms in urban and rural areas of China. Because urban parents often lack the time and energy to look after their little child, grandparents take on the responsibility of caring for the grandchildren. In rural areas, grandparents act as "guardians" who raise stay-at-home grandchild because their grown-up children have migrated to cities for work.

Different theories offer explanations of grandparental care for grandchildren. Some scholars argue that the family intergenerational relationship in China is a kind of cooperative group model (Lee et al. 1994; Zhang and Li 2004) and that the behavior of grandparents caring for grandchildren is mutually beneficial to the grandparents and their grown-up children. It facilitates the grown-up children to work and obtain income, and decreases the living pressures they experience. At the same time, the care for grandchildren represents an intergenerational exchange of resources, one that contributes to improve family support for elderly parents when they are in need of care (Silverstein et al. 2007; Song and Li 2010). Yang and He (2004) think that the elderly have a strong "responsibility ethic" that emphasizes obligations to their offspring, and as a result, elderly parents are prepared to support their grown-up children and grandchildren in daily life regardless of reciprocation. Some scholars find that the elderly are driven mostly by selfless motivations, with care for grandchildren demonstrating altruism and self-sacrifice (Sun and Zhang 2013; Li and Feng 2016). Care for grandchildren provided by elderly parents gives grown-up children more opportunities to participate in the labor market and increase their incomes (Baker and Siliverstein 2012). Survey data show that caring for stay-at-home grandchild obviously increases intergenerational wealth transfers from grown-up children to elderly parents in rural areas (Song and Li 2010; Tian et al. 2016). It is necessary to determine whether the elderly parents of first-generation only-children receive more support from grown-up only-children after caring for grandchildren. And the motivation of elderly parents to care for grandchildren and the characteristics of intergenerational relationships in only-child families will also be revealed.

In China's traditional patrilineal family system, in a multiple-child family the son is responsible for supporting the parents, and elderly parents prefer to care for the son's children (Chen and Liu 2012; Silverstein et al. 2007; Cong and Silverstein 2008; Friedman et al. 2008). Caring for the grandchildren of daughters was considered to be a sort of "dividend" (Xu 2001), and daughters in receipt of this dividend were likely to offer reciprocal support to parents in return. Only-child families have only a single son or daughter to undertake family support responsibilities. Certain aspects of the situation in only-child families need further exploration: Are there differences in the care provided by grandparents with a single son versus that provided 
by grandparents with a single daughter? Do single sons and single daughters provide different levels of support for their elderly parents due to different levels of care for grandchildren by elderly parents?

In addition, intergenerational family support is closely linked to the needs of the elderly parents (Hermalin et al. 1990; Chen 1998; Wang 2010), and is affected by the age, health conditions and economic conditions of these individuals (Eggebeen 1992; Zhang and Li 2004). Living arrangements apparently have an impact on the support grown-up children provide for elderly parents (Yan et al. 2001). Investments in their children by parents, such as the provision of education, effectively increase the probability that grown children will provide support for their elderly parents (Chen 1998). Compared to children from multiple-child families, only-children who are employed, married or have babies of their own are likely to give a higher level of economic support to parents who are around 50 years old (Song and Huang 2011). A thorough analysis is needed to understand the impact grandparental care for grandchildren may have on the provision of support provided to elderly parents by first-generation only-children in urban China. This analysis must take into consideration parent-child living arrangements and the specific situation of individual parents and children.

\section{Data and methods}

\subsection{Data}

This study relies primarily on data from the 2015 Survey of First-Generational OnlyChild Family in Urban China conducted by the Institute of Population and Labor Economics, Chinese Academy of Social Sciences. The survey adopted a stratified multistage PPS design and combined indicators for the economy and the population. Chongqing Municipality, Hubei Province, Shandong Province, Gansu Province and Heilongjiang Province were chosen randomly as provincial level units. Within a provincial unit, six districts were chosen randomly from three cities (the provincial capital, a secondary city and a prefecture-level city). Five communities were then chosen randomly from each district, and 21 only-child families were chosen randomly from each community. In each only-child family with a child born in or between the years 1975-1985, the father or mother was surveyed. The survey covered the eastern, central, western and northeastern regions of China, and was generally representative of conditions in China in terms of geographical locations and socio-economic development levels. The survey obtained 3093 effective samples, including 1172 elderly parents aged 60 and above whose children had married and given birth.

\subsection{Research methods}

This paper examines the status of grandparental care for grandchildren and of support for elderly parents provided by only-children. A multiple regression analysis 
method is used to analyze the determinants of family support for the elderly in onlychild families.

The dependent variables in the regression analysis are economic support, housekeeping support and emotional support given by grown-up children to their elderly parents. Economic support refers to the total value of the cash and material objects provided to parents by their grown-up children during the 12 months prior to the survey. To eliminate the impact of data differences on analysis results, the value of logarithmic operations, $\mathrm{Ln}(\mathrm{N}+1)$ (where $\mathrm{N}$ is the actual value of the economic support) is used. The value of the housekeeping support is assigned according to "the time that an only-child couple helped elderly parents with housekeeping during the past 12 months" $(0=$ never, $1=$ several times or once a year, $2=$ several times a month, $3=$ several times a week, $4=$ everyday). The value of emotional support is assigned based on responses to the question "does your child like to listen to you when you talk to them about your worries or difficulties?" $(0=$ elderly parents do not like to talk to their grown-up children, $1=$ grown-up children never like to listen, $2=$ sometimes like to listen, $3=$ always like to listen).

Independent variables in the regression analysis cover situations of care for grandchildren by grandparents and individual factors of the grandparents and grownup children. Individual factors of grandparents include gender, age, marital status, health status, and income in 2014 , whether the individual has a pension, whether the individual owns a house, and the distance between the residence of the individual and his/her grown-up children at time of the survey. Individual factors of grown-up child include gender, age, education level, whether the individual owns a house, and income in 2014 (a natural logarithm is calculated). Also of note, the characteristics of parent-child relationships differ somewhat from region to region due to cultural variations and different ethnicities. Different levels of socio-economic development also impart family relationships (Yang and $\mathrm{He} 2004$ ) and, as a result, location variables are also included in the regression analysis model to describe factors that influence family support.

\section{Major findings}

\subsection{The status of grandparental care for grandchildren}

Responses to the survey question "Did you help your grown child to care for your grandchildren?" show that over $85 \%$ of the parents of first-generation only-children in urban China cared for their grandchildren. Nearly half of these grandparents took on all or almost all of the responsibility for the care for grandchildren. Elderly parents with a single son were more likely to care for their grandchildren than elderly parents with a single daughter. In particular, the percentage of only-son parents who took on almost all responsibility for the care for grandchildren was higher than that of only-daughter parents. Also the percentage of only-son parents who seldom or never cared for grandchildren was lower than that of only-daughter parents. The statistical results show significant differences between care for grandchildren provided by elderly only-son parents and only-daughter parents (see Table 1). 
Table 1 The overall status of caring for grandchild (\%)

\begin{tabular}{ccccccccc}
\hline $\begin{array}{c}\text { Gender } \\
\text { of child }\end{array}$ & $\begin{array}{c}\text { Almost } \\
\text { all }\end{array}$ & $\begin{array}{c}\text { Over } \\
\text { half }\end{array}$ & $\begin{array}{c}\text { About } \\
\text { half }\end{array}$ & $\begin{array}{c}\text { Less than } \\
\text { half }\end{array}$ & Seldom & Never & $\begin{array}{c}\text { Chi-square } \\
\text { value (df) }\end{array}$ & $\begin{array}{c}\text { Sample } \\
\text { size }\end{array}$ \\
\hline Son & 53.93 & 16.01 & 9.21 & 9.06 & 8.01 & 3.78 & $21.91(5) * * *$ & 662 \\
Daughter & 41.96 & 16.67 & 10.59 & 13.33 & 13.33 & 4.12 & 510 \\
In total & 48.72 & 16.30 & 9.81 & 10.92 & 10.32 & 3.92 & & 1172 \\
\hline
\end{tabular}

$* * * \mathrm{p}<0.001, * * \mathrm{p}<0.01,{ }^{*} \mathrm{p}<0.05,{ }^{+} \mathrm{p}<0.1, n s$ is not significant

\subsection{Status of support for the elderly}

The current status of support for the elderly parents of only children includes the circumstances of economic support, household support and emotional support provided to elderly parents by their children during the 12 months prior to the survey.

\subsubsection{Economic support}

Economic support is considered both in terms of the frequency with which it is provided and the amounts given. According to Table 2, about 35\% of onlychildren often provided money and material objects to their parents during the 12 months period prior to the survey, over $40 \%$ provided occasional support, and more than $20 \%$ provided no support. The percentage of only-daughters giving economic support to parents was higher than that of only-sons, and the percentage of only-daughters who never gave economic support to parents was lower than that of only-sons.

Table 2 Frequency of economic support for elderly parents (\%)

\begin{tabular}{ccccccc}
\hline $\begin{array}{c}\text { Gender of } \\
\text { only-child }\end{array}$ & $\begin{array}{c}\text { Caring for } \\
\text { grandchildren }\end{array}$ & Often & Occasionally & Never & $\begin{array}{c}\text { Chi-square } \\
\text { value (df) }\end{array}$ & $\begin{array}{c}\text { Sample } \\
\text { size }\end{array}$ \\
\hline \multirow{3}{*}{ Son } & Not caring & 24.68 & 45.45 & 29.87 & $3.08(2)$ & 77 \\
& Caring & 34.36 & 41.54 & 24.1 & & 585 \\
& Total & 33.23 & 41.99 & 24.77 & & 662 \\
\hline \multirow{3}{*}{ Daughter } & Not caring & 28.89 & 46.67 & 24.44 & \multirow{2}{*}{$2.78(2)$} & 90 \\
& Caring & 38.10 & 41.67 & 20.24 & & 420 \\
& Total & 36.47 & 42.55 & 20.98 & & 510 \\
\hline \multirow{3}{*}{ Total } & Not caring & 26.95 & 46.11 & 26.95 & \multirow{2}{*}{$5.25(2)+$} & 167 \\
& Caring & 35.92 & 41.59 & 22.49 & & 1005 \\
& Total & 34.64 & 42.24 & 23.12 & & 1172 \\
\hline
\end{tabular}

$* * * \mathrm{p}<0.001, * * \mathrm{p}<0.01,{ }^{*} \mathrm{p}<0.05,{ }^{+} \mathrm{p}<0.1, n s$ is not significant 
The economic support (see Table 3) shows that the average amount of financial support given to parents by only-children during the 12 months prior to the survey was CNY 3484; large standard deviation values show differences in the amounts given in different families. The average amount given by only-sons was lower than that given by only-daughters.

When all elderly parents, those with only-sons and those with only-daughters, are considered together, the average amount of economic support received by those parents who cared for grandchildren was lower than that received by parents who did not care the grandchildren. Large standard deviation also shows great differences in the economic amounts of support received by elderly parents who cared for grandchildren.

Only-son elderly parents who cared for grandchildren received more economic support on average than did only-son elderly parents who did not care for grandchildren. The average amount of economic support received by only-daughter elderly parents who cared for grandchildren was lower than the support received by only-daughter parents who did not care for grandchildren. Overall, the economic support received by elderly parents who did not care for grandchildren was greater than that received by elderly parents who did care for grandchildren. This may be because families with moderate or limited income have no alternative but to have elderly parents care for children, while families with better economic conditions can employ babysitters to care for children. The findings here indicate that the economic support given by grown-up child to elderly parents does not depend entirely on the childcare support elderly parents provide their only-children. The level of support depends mainly on the economic conditions of the grown-up only-children. Also of note, a relatively small sample of elderly parents did not care for grandchildren versus a much larger sample that did care for grandchildren, so the possibility that sample size impacted analysis results cannot be ignored.

\subsubsection{Housekeeping support}

According to Table 4, the percentage of only-child couples who never helped elderly parents with housekeeping is the highest, and the percentage of only-child couples who seldom provided housekeeping support for elderly parents is noticeably greater than the percentages of grown-up children who helped with housekeeping every day or every week. Over $70 \%$ of elderly parents who did not care for their grandchildren seldom or never received housekeeping support provided by their only-children. The percentage of those who cared for grandchildren and who received housekeeping support provided by grown-up children almost every day or every week is obviously higher than the percentage of those receiving housekeeping support who did not care for grandchildren.

The above results show that elderly parents received relatively limited housekeeping support provided by their only-children. Elderly parents who cared for grandchildren received more housekeeping support than those who did not care for grandchildren. 


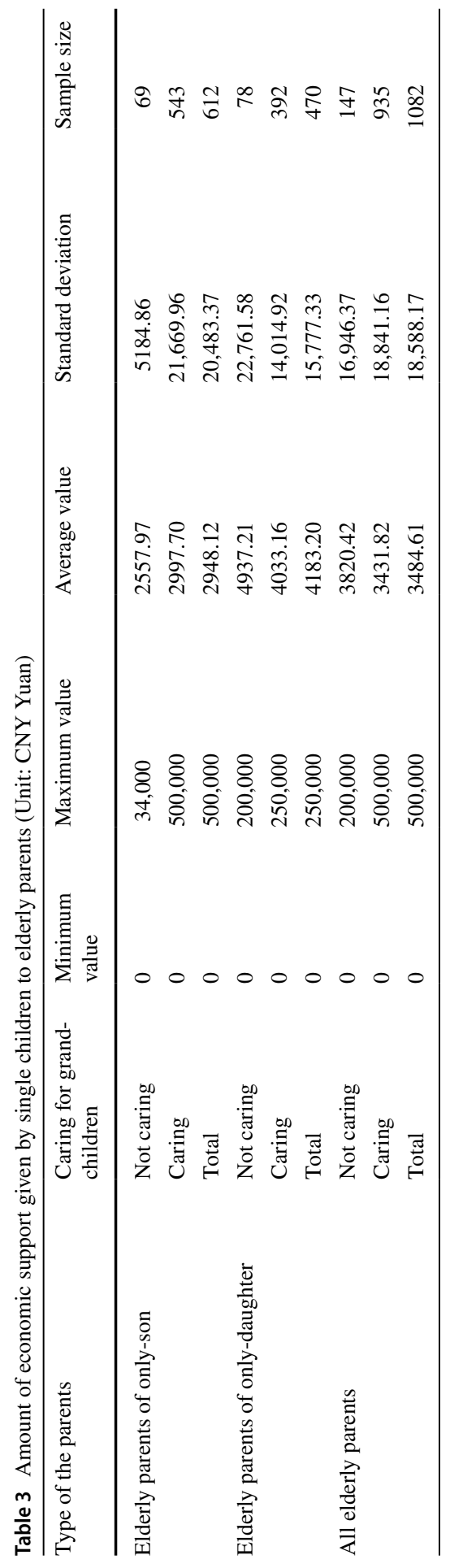




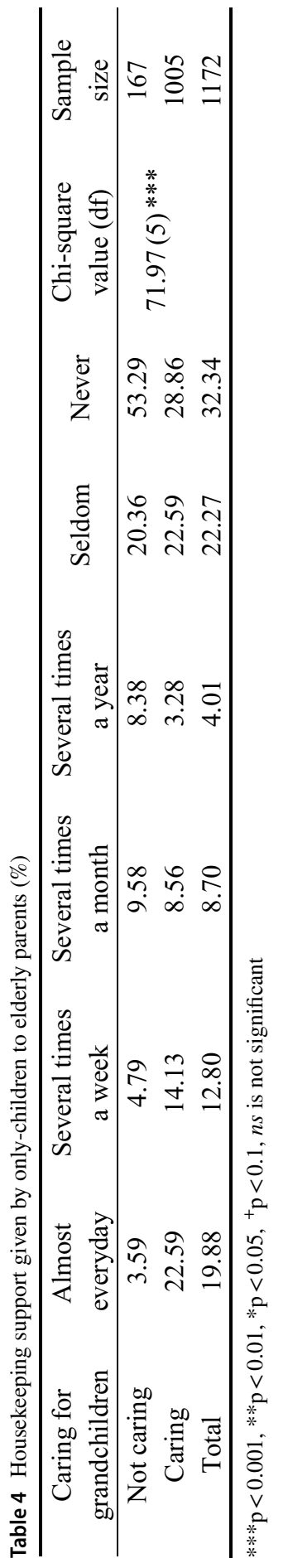




\subsubsection{Emotional support}

Table 5 shows first that some elderly parents were not willing to share their thoughts or difficulties with their only-children. At the same time, more than $60 \%$ of only-children were always willing to listen to their elderly parents talk about their thoughts and difficulties, while the percentages of only-children who were only sometimes or never willing to listen were relatively low. Elderly parents who did care for grandchildren received more emotional support than those who did not care for grandchildren, but difference in emotional support between parents caring for and not caring grandchildren is not statistically significant.

\subsection{Results of the regression analysis of determinants of family support for the elderly}

Table 6 presents descriptions of the variables and the results of the regression analysis of the determinants affecting family support for the elderly parents of the firstgeneration only-children in urban China. The distribution of the variables shows that most elderly parents of only-children cared for their grandchildren. There is above $40 \%$ of married couple families, and so do only-child parents living in lineal families with two or more generations. Nearly $40 \%$ of only-children live with elderly parents.

The regression analysis results let us draw the following conclusions with respect to the support provided for elderly parents by only-children. First, the analysis of factors influencing economic support shows that elderly only-child fathers or mothers living alone got significantly less support than elderly only-child couples living together. The better the parent-child relationship, the more the economic support children provided for their elderly parents. Only-child fathers may receive less economic support than only-child mothers, while only-child fathers or mothers who were widowed or divorced received relatively more economic support. The economic support that only-sons gave elderly parents was significantly less than the economic support provided by only-daughters. Only-children with bachelor's or more advanced degrees provided more economic support to elderly parents. Only-children with annual incomes of CNY 80 thousand or more also gave more economic support to elderly parents. Finally, only-children from Shandong Province apparently gave more economic supports than those from Heilongjiang Province.

Table 5 Emotional support provided by only-children to their elderly parents (\%)

\begin{tabular}{ccccccc}
\hline $\begin{array}{c}\text { Caring for } \\
\text { grandchildren }\end{array}$ & $\begin{array}{c}\text { Never } \\
\text { willing } \\
\text { to listen }\end{array}$ & $\begin{array}{c}\text { Sometimes } \\
\text { willing to } \\
\text { listen }\end{array}$ & $\begin{array}{c}\text { Always } \\
\text { willing } \\
\text { to listen }\end{array}$ & $\begin{array}{c}\text { Parents } \\
\text { not willing } \\
\text { to talk }\end{array}$ & $\begin{array}{c}\text { Chi-square } \\
\text { value (df) }\end{array}$ & $\begin{array}{c}\text { Sample } \\
\text { size }\end{array}$ \\
\hline Not caring & 10.78 & 12.57 & 55.69 & 20.96 & $5.42(3)$ ns & 167 \\
Caring & 6.87 & 9.95 & 63.48 & 19.70 & & 1005 \\
Total & 7.42 & 10.32 & 62.37 & 19.88 & & 1172 \\
\hline
\end{tabular}

$* * * \mathrm{p}<0.001, * * \mathrm{p}<0.01, * \mathrm{p}<0.05,{ }^{+} \mathrm{p}<0.1$, ns is not significant 


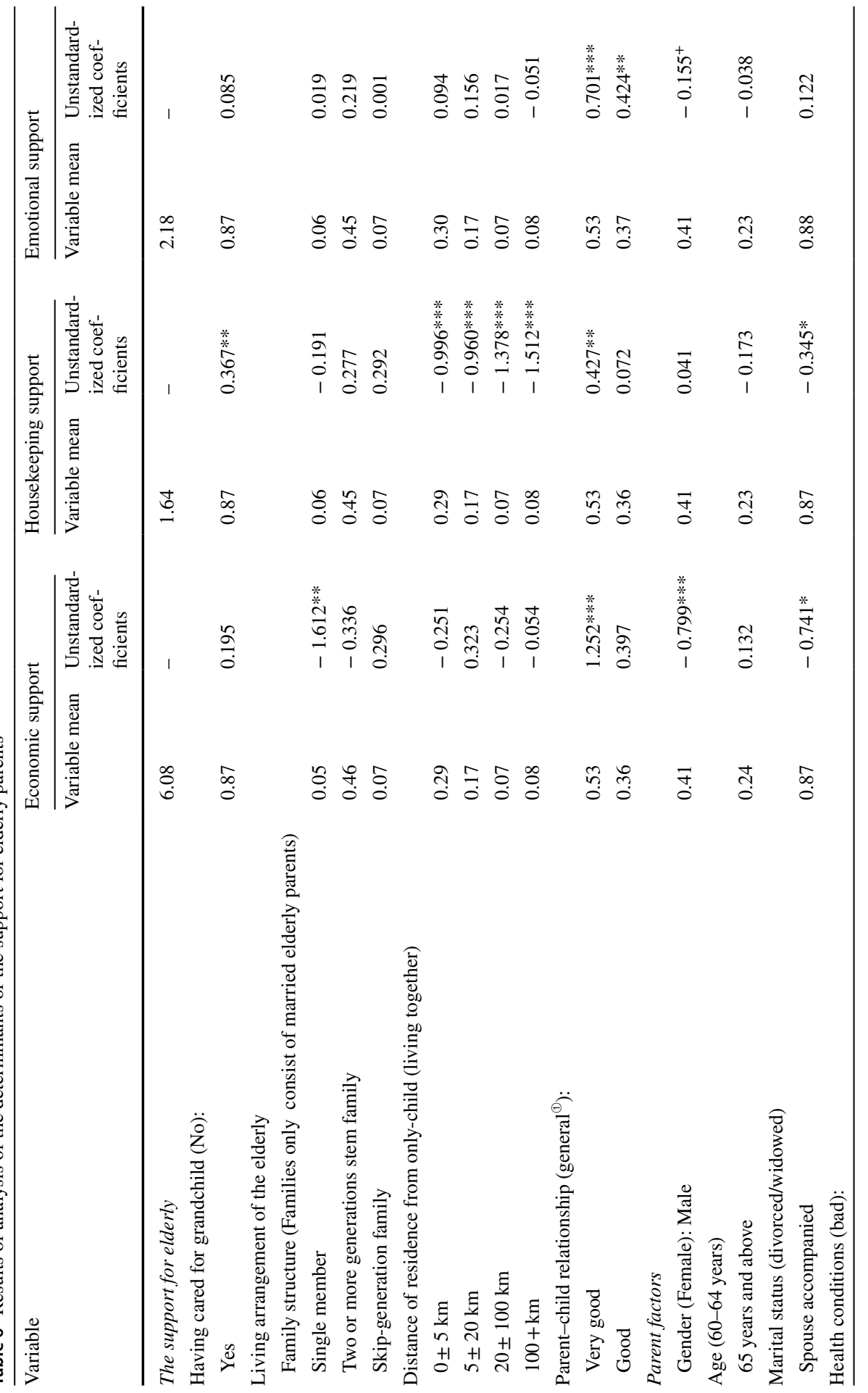




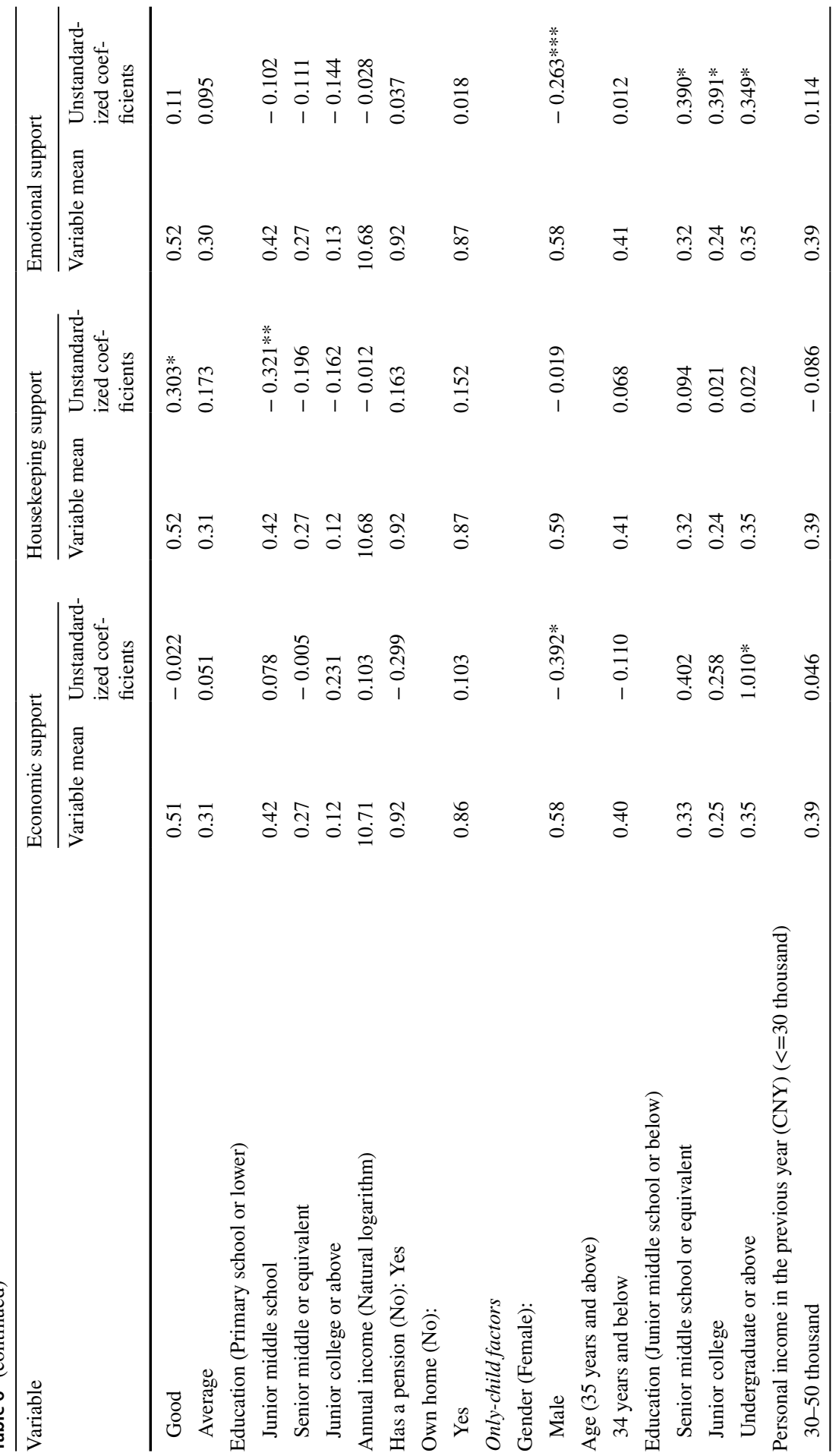




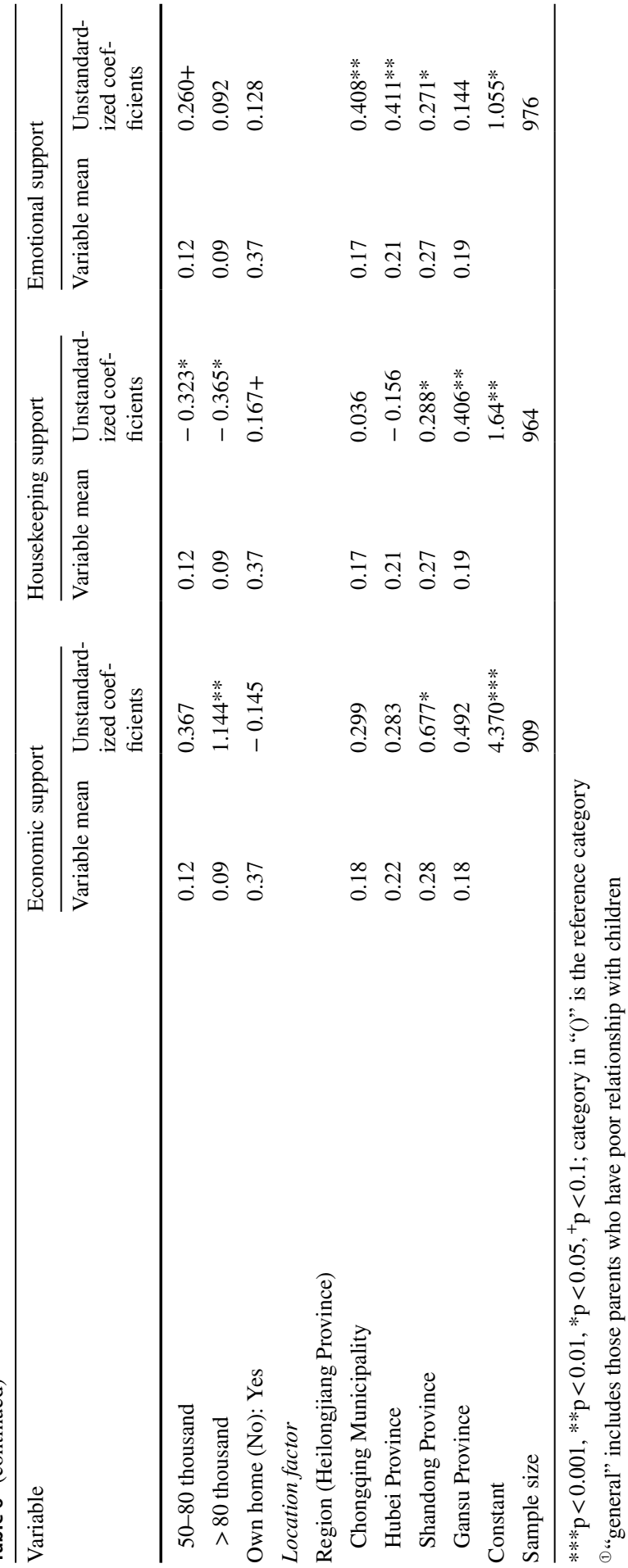


Second, the analysis of factors influencing housekeeping support for elderly parents reveals that those who cared for grandchildren generally got more housekeeping support than those who did not care for grandchildren. The further elderly parents lived from their only-children, the less likely they were to receive housekeeping support from their child. Elderly parents living with their only-child got more housekeeping support than other elderly parents. The better the everyday relationship between elderly parents and their only-child, the more likely the parents were to get housekeeping support. Elderly couples are more likely to receive less housekeeping support from only-children than widowed or divorced parents. Elderly parents in good physical condition generally got more housekeeping support. Only-children with junior high school or less educational achievement provided less housekeeping support. Only-children whose annual income was over CNY 50 thousand provided less housekeeping support to their elderly parents. Only-children from Shandong Province and Gansu Province generally provided more housekeeping support for elderly parents than did only-children from the other provinces included in this study.

Last, the analysis of factors influencing the provision of emotional support reveals that the better the everyday relationship between elderly parents and their only-children, the more emotional support the parents got. Only-children gave less emotional support to elderly fathers than they did to elderly mothers, and only-sons generally gave less emotional support to elderly parents than did only-daughters. The higher the education level the only-child had, the more likely the only-child was to provide emotional support to his/her elderly parents. Only-children with annual incomes of CNY 50-80 thousand gave more emotional support to parents, and onlychildren from Chongqing Municipality, Hubei Province and Shandong Province provided more emotional support than did only-children from Gansu and Heilongjiang Provinces.

The results of the analysis show that the care elderly parents provided for grandchildren only significantly impacted the housekeeping support provided by grownup children; care giving did not influence the provision of economic or emotional support. The living arrangements of elderly parents and the quality of parent-child relationships, as well as gender and marital status of the parents all obviously impacted the support received by elderly parents. The better the parent-child relationship was, the more economic support an only-child provided for parents. Onlychildren gave more economic support to an elderly parent who was female, divorced or widowed. Only-children with higher education levels and more annual income give more economic and emotional support to elderly parents. However, only-children with higher incomes gave less housekeeping support to elderly parents.

\section{Conclusions and discussions}

This paper has drawn on survey data about first-generation only-child families in urban China in 2015 to analyze the status of care for grandchildren provided by the elderly parents of first-generation only-children, and then examine the impact 
such childcare activities had on the support provided to elderly parents by onlychildren. The conclusions are as follows:

First, over $80 \%$ of the elderly parents included in this study helped to care for grandchildren. The percentage of the elderly parents with an only-son who cared for grandchildren was higher than the percentage of parents with an only-daughter, but the difference is not large. The results show that elderly parents did not show gender preference in the care for grandchildren; only-son parents cared for grandchildren, and only-daughter parents also cared for grandchildren.

Second, most only-children provided some combination of economic support, housekeeping support and emotional support for their elderly parents. In other words, the majority of only-children took responsibility for the support of elderly parents. From the perspective of frequency of economic support provided by only-children, elderly parents who cared for grandchildren often received more economic support, housekeeping support and emotional support than those who did not care for grandchildren. However, the average amount of the economic support received by elderly parents who cared for grandchildren was obviously less than that received by those who did not. This may be attributable to differences in the economic conditions of the only-children. Only-child families with good economic conditions can afford to employ babysitters, while families with less income often ask elderly parents to care for children in order to limit household expenditures. Only-child families with lower incomes also gave less economic support to elderly parents due to financial constraints.

Third, caring for grandchildren had a certain impact on the support only-children provided for elderly parents. Caring for grandchildren helped to increase the economic support, housekeeping support and emotional support given to elderly, but only the impact on housekeeping support was statistically significant. Therefore, the care for grandchildren by elderly parents of only-children in urban China does not provide evidence of a wealth transfer from grown-up children to elderly parents. This is inconsistent with the fact that the care for stay-at-home grandchildren by elderly parents obviously increases the intergenerational transfer of wealth from grown-up children to elderly parents in rural areas (Song and Li 2010; Tian et al. 2016). In urban China, most elderly only-child parents have stable incomes, and do not have to depend on their child for economic support. Under double pressures of employment competition and care for children, it is an optimal choice for only-children to let elderly parents care for grandchildren. As the only child in the family, most adult only-children have strong dependences on parents in daily life, including having elderly parents care for children ( $\mathrm{Li}$ and Feng 2016). So many adult children did not transfer wealth to elderly parents who helped to care for the grandchildren in return. To a certain extent, care for grandchildren by the elderly parents of first-generation only-children in urban China does more to meet the needs of grown-up children than it does to benefit the elderly parents of those children The behavior of elderly parents is fully altruistic. Elderly parents have only one child and majority of them have good relationship with adult only-child, and especially most mothers or mother-in-law of only-child have spare time to care for grandchildren, so they are willing to help their child to 
care for grandchildren. Certainly, some parents voluntarily help the only-child to take care of grandchildren in order to get more happiness in daily time.

Fourth, individual factors, such as the sex, age, marital status, education level and health status of the elderly parent(s), and the education level and annual income of the only-children had significant impacts on the support for elderly parents. Elderly parents who are female, divorced or widowed received more economic support. Only-children with higher education levels and annual income gave more economic and emotional support to elderly parents. However, only-children with higher annual incomes gave less housekeeping support to elderly parents. These results fully demonstrate that family supports provided by adult child were mostly influenced by the need of elderly parents and the resources available to their only-children. Elderly couples living together and not separated by death or divorce can support each other in daily life and have limited need of support provided by their only-children. However, a single elderly parent living alone lacks the daily care and emotional support of a spouse and needs more support provided by an only-child. At the same time, the ability of only-children to provide support for parents depends on the resources they have available as well as the needs of the elderly parents. In general, only-children are the primary beneficiaries of the care for grandchildren provided by elderly parents. If the elderly parents' need of family support is low, caring for grandchildren is mainly a kind of altruistic behavior. When the demands of elderly parents increase, the extent to which only-children can satisfy these demands depends on the financial, time and other resources the children have available.

In addition, most of the elderly parents of only-children interviewed for this survey were still relatively young and had limited needs for family support. As the age of parents increases, their demand for family support will gradually increase. Whether the altruism that the parental generation currently demonstrates in intergenerational interactions in only-child families will weaken is a subject for future research.

\section{References}

Attias-Donfut, C., Ogg, J., \& Wolff, F.-C. (2005). European patterns of intergenerational financial and time transfers. European Journal of Ageing, 2(3), 161-173.

Baker, L., Siliverstein, M. (2012). The wellbeing of grandparents caring for grandchild in China and the United States. In S. Arber, V. Timonen (Eds.), Contemporary grandparents: Changing family relationships in global contexts (pp. 51-70). Oxford University Express.

Chen, J. M. (1998). Investment and supports-causal analysis on the intergenerational exchanges of urban residents. Social Sciences in China., 6, 131-149.

Chen, F., \& Liu, G. (2012). The health implications of grandparents caring for grandchild in China. Journals of Gerontology., 67(1), 99-112.

Cong, Z., \& Silverstein, M. (2008). Intergenerational time-for-money exchanges in rural China: Does reciprocity reduce depressive symptoms of older grandparents? Research in Human Development., 5, 6-25.

Eggebeen, D. J. (1992). Family structure and intergenerational exchanges. Research on Aging., 14, $427-447$.

Feng, X. T. (2006). The only-child in China: Scale, differences and comments. Theory Monthly., 4, 7-12.

Friedman, D., Hechter, M., \& Kreager, D. (2008). A theory of the value of grandchildren. Rationality and Society., 20(1), 33-63. 
Giarrusso, R., Silverstein, M., Feng, D., \& Marenco, A. (2000). Primary and secondary stressors of grandparents raising grandchildren: Evidence from a national survey. Journal of Mental Health and Aging., 6, 291-310.

Hermalin, A.I., M.C. Chang, H.S. Lin, M.L. Lee, \& M.B. Ofstedal. (1990). Patterns of support among the elderly in Taiwan and their policy implications. Comparative study of the elderly in Asia research reports (pp. 90-94). Ann Arbor: Population Studies Center, University of Michigan.

Hughes, M., Waite, L., LaPierre, T., \& Luo, Y. (2007). All in the family: The impact of caring for grandchild on grandparents' health. The Journals of Gerontology, Series B: Psychological Sciences and Social Sciences., 62, 108-119.

Ko, P.-C., \& Hank, K. (2014). Grandparents caring for grandchild in China and Korea: Findings from Charls and Klosa. Journals of Gerontology. Series B, Psychological Sciences and Social Sciences, 69(4), 646-651.

Lee, Y. J., Parish, W. L., \& Willis, R. J. (1994). Sons, Daughters, and Intergenerational Support for the Elderly in Taiwan. American Journal of Sociology, 99(4), 1010-1041.

Li, F., \& Feng, X. T. (2016). The willingness and influencing factors of grandparents care for the coming grandchildren in cities. Population and Development., 4, 87-96.

Silverstein, M., Cong, Z., \& Li, S. (2007). Grandparents who care for their grandchild in rural China: Benefactors and beneficiaries. In I. Cook \& J. Powell (Eds.), New perspectives on China and aging (pp. 49-71). New York: Nova Science.

Song, J. (2005). Only-children and only-child families in China. Population Research., 2, 17-25. (+96).

Song, J., \& Huang, F. (2011). Intergenerational relationship between only-children and their parents. Population Research., 5, 3-16.

Song, L., \& Li, S. Z. (2010). The impact of caring for grandchildren on intergenerational support of the elderly in rural China. Population Journal., 2, 35-42.

Sun, J. J., \& Zhang, H. K. (2013). The situation and influencing factors of Chinese older people taking care of their grandchildren. Population \& Economics., 4, 70-77.

Tian, Q., Guo, R. Y., \& Gao, T. M. (2016). The situation of intergenerational transfer of family wealth and the influencing factors: A study based on the CHARLS data. Jilin University Journal of Social Sciences Edition, 4, 16-27. (+188).

Triadó, C., Villar, F., Celdrán, M., \& Solé, C. (2014). Grandparents who provide auxiliary care for their grandchildren: Satisfaction, difficulties, and impact on their health and well-being. Journal of Intergenerational Relationships., 12(2), 113-127.

Wang, Y. S. (2008). Theoretical analysis on the intergenerational relationship in Chinese families. Population Research, 4, 13-21.

Wang, G. Z. (2009). The estimation of the total quantity, structure and their future development trend. Population Research., 1, 10-16.

Wang, Y. S. (2010). The intergenerational relationship in a wedding: The accumulation and transfer of family wealth-An investigation on village in eastern Hebei Province. China Rural Survey, 3, 60-72.

Xu, Y. (2001). Family support for old people in rural China. Social Policy and Administration, 35, 307-320.

Yan, S. M., Chen, J. M., \& Yang, S. H. (2001). The impact of living arrangements on the behavior of the support for the elderly. Social Sciences in China., 1, 130-140.

Yang, S. Z., \& Guo, Z. W. (2000). Chinese one-child situation and its impacts on future population development. Market and Demographic Analysis, 4, 11-18.

Yang, S. H., \& He, C. M. (2004). The ethics of responsibility and the family support in Beijing-An analysis based on the data from the survey carried out in 1999 for the demand of the aged in Beijing. Journal of Peking University (Philosophy and Social Sciences), 1, 71-84.

Zhang, W. J., \& Li, S. Z. (2004). Research on the family intergenerational support for the elderly in rural China-using exponentially mixing model to prove the cooperative group theory. Statistical Research., 5, 33-37. 


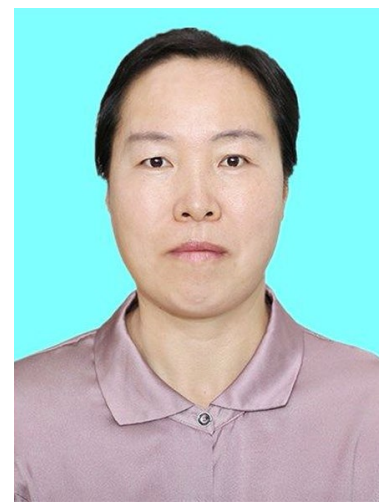

Haixia Wu focuses on Geriatric Sociology and Family Demography. Using survey data she reveals that offspring are the main beneficiaries of the intergenerational support in China. The gradual improvement of the social pension system has reduced the feedback from the offspring to the elderly parents, and the intergenerational imbalance has tended to expand. Family support, rather than community-based services, has substitution effect on institutional support for the elderly only-child aging parents in urban China. 